\title{
How Human Gait Responds to Muscle Impairment in Total Knee Arthroplasty Patients: Muscular Compensations and Articular Perturbations
}

\author{
Marzieh M.Ardestani*1,2 and Mehran Moazen ${ }^{3}$ \\ ${ }^{1}$ Department of Orthopedic Surgery, Rush University Medical Center, Chicago, IL 60612,USA \\ ${ }^{2}$ State Key Laboratory for Manufacturing System Engineering, School of Mechanical Engineering, Xi'an Jiaotong University, Xi'an, China \\ ${ }^{3}$ Department of Mechanical Engineering, University College London, Torrington Place, London WC1E 7JE, UK
}

*Address for corresponding author Marzieh M Ardestani (PhD)

Rush University Medical Center

1611 W. Harrison St., Suite 204

Chicago, IL-60612

Email:mostafavizadeh@yahoo.com

Word Count: Introduction to Discussion: 3559 words 


\begin{abstract}
Post-surgical muscle weakness is prevalent among patients who undergo total knee arthroplasty (TKA). We conducted a probabilistic multi-body dynamics (MBD) to determine whether and to what extent habitual gait patterns of TKA patients may accommodate strength deficits in lower extremity muscles. We analyzed muscular and articular compensations in response to various muscle impairments, and the minimum muscle strength requirements needed to preserve TKA gait patterns in its habitual status.

Muscle weakness was simulated by reducing the strength parameter of muscle models in MBD analysis. Using impaired models, muscle and joint forces were calculated and compared versus those from baseline gait i.e. TKA habitual gait before simulating muscle weakness. Comparisons were conducted using a relatively new statistical approach for the evaluation of gait waveforms, i.e. Spatial Parameter Mapping (SPM). Principal component analysis was then conducted on the MBD results to quantify the sensitivity of every joint force component to individual muscle impairment.

The results of this study contain clinically important, although preliminary, suggestions. Our findings suggested that: (1) hip flexor and ankle plantar flexor muscles compensated for hip extensor weakness; (2) hip extensor, hip adductor and ankle plantar flexor muscles compensated for hip flexor weakness; (3) hip and knee flexor muscles responded to hip abductor weakness; (4) knee flexor and hip abductor balanced hip adductor impairment; and (5) knee extensor and knee flexor weakness were compensated by hip extensor and hip flexor muscles. Future clinical studies are required to validate the results of this computational study.
\end{abstract}

Keywords: Human gait, Total knee arthroplasty, Rehabilitation, Muscle weakness, Joint force, Multi-body dynamics 


\section{Introduction}

Remarkable functional improvement and pain relief have been reported following total knee arthroplasty (TKA-(da Silva et al., 2014)). However, various factors such as joint instability(Yercan et al., 2005), muscle impairments (Schache et al., 2014, Yoshida et al., 2013) and pre-surgical gait adaptations (Ouellet and Moffet, 2002) often prevent patients to restore a "normal" gait pattern after surgery. Muscular impairment (i.e. strength decline) occurs frequently following TKA and may persist long after surgery(Bjerke et al., 2014, Davidson et al., 2013, Thomas et al., 2014, Yoshida et al., 2013, Farquhar et al., 2009). Recent studies have reported 50-60\% strength decline in hamstring and quadriceps (Judd et al., 2012, Stevens-Lapsley et al., 2010) that may persist up to three years after surgery (Schache et al., 2014).

A subtle weakness in an individual muscle can be compensated by additional contribution of other muscles (Goldberg and Neptune, 2007). However, severe muscle impairments, such as post-operative muscle deficits in TKA patients, may not be easily addressed by other muscles. As a matter of fact, patients will adapt to "kinematic" compensations so as to offload the impaired muscles. Quadriceps avoidance (Andriacchi, 1993) or knee stiffening (Benedetti et al., 2003) strategies are examples of such kinematic adaptations. The existent body of literature is rich with studies describing the abnormal gait characteristics of TKA patients compared to noninjured population(Alnahdi et al., 2011, Hatfield et al., 2011, McClelland et al., 2010, Yoshida et al., 2012). However, there are still various questions remaining on TKA patient gait patterns; e.g. how vulnerable the TKA habitual gait pattern is to any muscle impairment before kinematic adaptation may be demanded? and how muscle impairment may influence muscle and joint forces? While such questions have been investigated for noninjured subjects (Goldberg and Neptune, 2007, Thompson et al., 2013, Valente et al., 2013, van der Krogt et al., 2012), previous findings cannot be easily extrapolated to TKA subjects.

Beside, comprehensive investigation of all potential muscle impairments and their consequences on muscle and joint forces are currently lacking from literature as most previous studies simulated the weakness of only one (Thompson et al., 2013, Valente et al., 2013) or a few muscles (Knarr et al., 2013, Steele et al., 2012, van der Krogt et al., 2012). Also, from a technical point of view, previous studies documented muscular compensations in terms of scalar gait features (defined at discrete time points); e.g. "magnitudes" of muscle forces. Such an abstraction can oversimplify the complex gait waveforms and the underlying dynamic information. Therefore, a more holistic understanding of the muscular compensations throughout the entire gait cycle is required .

The overall aim of this study was to understand how TKA gait responds to muscle weakness . In particular, this study aimed to (1) quantify the minimum muscle strength requirements to execute habitual gait strategy (i.e. baseline gait), (2) identify the muscular compensations and joint force perturbations in response to an 
impaired muscle group and (3) quantify the sensitivity of joint forces due to weakness of various individual muscles. A probabilistic multi-body dynamic (MBD) approach was combined with statistical parameter mapping (SPM) and principal component analysis (PCA) to address the aforementioned technical shortcomings of previous studies. It should be pointed out that although TKA gait strategies contain some adaptations compared to noninjured counterpart; TKA habitual gait status is referred to "baseline" gait for the present study to imply the gait pattern before simulating muscle weakness in the musculoskeletal model.

\section{Methodology}

Experimental gait measurements of six TKA patients were adopted from a published repository (section 2.1). Three sets of MBD simulations were conducted: The first set of MBD simulations was called "baseline simulation" calculating the habitual muscle and joint forces for every subject (section 2.2). Second, individual muscles were systematically weakened until the baseline gait could no longer be executed by the musculoskeletal model unless by means of remarkable kinematic changes. From this set of simulations, the "minimum strength requirements" were determined (section 2.3). Third, muscles were impaired randomly by sampling their strength parameters in muscle models between the "minimum requirements" and their "nominal" values from the baseline simulation. Once again, muscle and joint forces were calculated using the impaired musculoskeletal models (section 2.3). Using SPM analysis, muscle and joint forces from impaired simulations were compared versus those obtained from baseline simulations (section 2.4). PCA was then used to quantify the sensitivity of joint forces due to the weakness of each individual muscle (section 2.5).

\subsection{Experimental gait data}

Gait data, i.e. ground reaction forces (GRF) and marker trajectories, from six TKA patients (five males, one female; height: $170.8 \pm 5.2 \mathrm{~cm}$; mass: $69.7 \pm 4.4 \mathrm{~kg}$ ), walking at self-selected pace, were adopted from a published repository (https://simtk.org/home/kneeloads, accessed Sept 2014). These patients were implanted with sensor-based knee prostheses that could measure in vivo knee forces. GRFs were measured at a frequency of 1000 $\mathrm{Hz}$ (Force plate, AMTI Corp., Watertown, MA, USA) and marker trajectory data were recorded at a frequency of $200 \mathrm{~Hz}$ (10-camera motion capture system, Motion Analysis Corp., Santa Rosa, CA, USA) using a modified Cleveland Clinic marker set with extra markers on the feet and trunk. Electromyography (EMG) signals were recorded at a frequency of $1000 \mathrm{~Hz}$ (Surface electrodes, Delsys Corp., Boston, MA, USA) for several muscle groups including: semimembranosus, biceps femoris long head, vastus medialis, vastus lateralis, rectus femoris, medial gastrocnemius, lateral gastrocnemius, and tensor fascia latae. For a complete description of this database see (Fregly et al., 2012, Kinney et al., 2013). Experimental EMG measurements were band-pass filtered with a $6^{\text {th }}$ order Butterworth within the frequency of 20-420 Hz. Root mean square (RMS) was computed within 30 msec intervals with $15 \mathrm{msec}$ overlap. The magnitudes of EMG measurements for every subject were normalized to the 
corresponding maximum values over all his/her gait trials. The average of normalized RMS computations were then compared versus those computed by MBD analysis for validation purposes.

\subsection{Multi-body dynamic analysis}

\subsubsection{Musculoskeletal model}

A 3D musculoskeletal model, based on the University of Twente Lower Extremity Model (TLEM -(Klein Horsman, 2007), was recruited in the multi-body simulation software, AnyBody Modeling System (version 5.2, AnyBody Technology, Aalborg, Denmark). In brief, the model included trunk, pelvis, thigh, shank and foot segments (Figure 1). Hip joint was modeled with three degrees of freedom (DOF) while knee joint was modeled as a hinge joint with only one DOF for flexion-extension and universal joint was considered for ankle-subtalar complex. TLEM model had 160 Hill-type muscle-tendon actuators and the strength of each muscle was modeled as follows (AnyBody Modelling System, User's Guide):

$$
\text { Strength }=F_{0}\left(2 \frac{L_{m}}{\overline{L_{f}}}-1\right)\left(1-\frac{L_{m}{ }^{\prime}}{V_{0}}\right)
$$

Where $F_{0}$ is the strength of the muscle at neutral fiber length $\left(\overline{L_{f}}\right)$ and contraction velocity $\left(\mathrm{L}_{\mathrm{m}}{ }^{\prime}\right)$ equals to zero. $L_{m}$ is the current length of the contractile element and $V_{0}$ is the contraction velocity at maximum voluntary contraction. $F_{0}$ is related to muscle isometric strength and has been estimated from cadaveric studies (Klein Horsman, 2007). Muscle groups and corresponding individual muscles are described in Table 1. The generic musculoskeletal model was scaled to each patient based on a Length-Mass-Fat scaling law in which body mass, body height and segment length were taken into account (Ali et al., 2013, Worsley et al., 2011). Body segment lengths were calculated based on the markers' coordination data in an optimization routine in which the model was scaled such that the differences between "model marker" and the "experimental marker" trajectories were minimized. For every subject, isometric muscle strengths $\left(\mathrm{F}_{0}\right)$ were also scaled based on a Height-Squared law (Jaric, 2002) and were considered as "nominal" strengths corresponding to "baseline" simulations. Muscle weakness was then simulated by reducing the $\mathrm{F}_{0}$ values. 


\subsubsection{Baseline simulation}

The scaled musculoskeletal model was recruited in an inverse dynamic analysis to calculate muscle and joint forces based on marker trajectories and GRFs. Joint forces were calculated from equilibrium equations whilst muscle forces were calculated in an optimization framework (Damsgaard et al., 2006):

$$
\begin{aligned}
& \text { Minimize }_{f} G\left(f^{(M)}\right), \quad G\left(f^{(M)}\right)=\operatorname{Max}\left(\frac{f_{i}^{(M)}}{N_{i}}\right) \\
& \text { Subject to }: C \times f=d \quad \text { and } \quad 0 \leq f_{i}^{(M)} \leq N_{i} \quad i=\left\{1, \ldots, n^{(M)}\right\}
\end{aligned}
$$

Where $G$ is the the objective function, $f=[f(M), f(R)]$ refers to all unknown forces including muscle forces $\left(f^{(M)}\right)$ and joint reaction forces $\left(f^{(R)}\right) . N_{i}$ is the strength of the muscle as defined in equation (1). $C$ is the coefficient-matrix for the unknown forces and $d$ contains all known applied loads and inertia forces. Muscle recruitment was computed in order to minimize the maximum muscle activities subject to positive muscle force constraints and equilibrium constraints. For a detailed discussion about numerical and physiological benefits of the aforementioned muscle recruitment criterion, see (Damsgaard et al., 2006, Rasmussen et al., 2001). Muscle and joint forces were then normalized to 100 samples to represent a gait cycle from heel strike $(0 \%)$ to the following heel strike (100\%) of the same leg (MATLAB v. 2009, the MathWorks, Inc. MA, USA). It should be pointed out that this set of MBD simulations implied the TKA daily habitual gait strategies (referred as baseline simulations).

\subsection{Muscle-impaired simulation}

Eight muscle groups, listed in Table 1, were chosen to be weakened, one at a time. First, each muscle group was impaired progressively by simultaneous weakening of its individual muscles; i.e. reducing the $F_{0}$ values from their nominal values in steps of $2 \%$, until the musculoskeletal model could no longer execute the baseline gait pattern of the subject unless with remarkable kinematic changes (van der Krogt et al., 2012) . From this set of simulations, the minimum strength requirement of each muscle group was identified. Second, each muscle group was weakened by simultaneous randomization of its individual muscles between their minimum and nominal strengths using Latin hypercube sampling (LHS-(Iman, 2008)). In the LHS technique, the strength space of each individual muscle was divided into 200 equal-probability intervals and one sample was chosen from each interval to ensure an equal coverage of the whole sampling space. In other words, a weakened muscle group was simulated by a set of 200 different perturbations of its individual muscles. Once again, inverse dynamic simulation was repeated using impaired musculoskeletal models to calculate joint angles, muscle forces and joint forces. If the calculated joint angles (hip flexion-extension, hip abduction-adduction, hip rotation, knee flexionextension, ankle flexion-extension and ankle rotation) were within two degrees of the baseline kinematics, the 
executed muscle and joint forces were chosen for further statistical analysis (Thompson et al., 2013). It should be pointed out that for each subject, a total of 1651 MBD simulations were conducted ( 1 baseline simulation +50 stepwise strength reducing simulations $+[8$ muscle groups $\times 200]$ probabilistic simulations).

\subsection{Statistical parameter mapping (SPM)}

SPM analysis, a vector-field statistical test for continuous-level statistical comparison, was recruited to perform a paired t-test $(\operatorname{SPM}(\mathrm{t}))$ on loading patterns between "baseline" and "muscle-impaired" simulations. This technique has been first used for 3D image comparison(Friston et al., 1994) and has been recently used in the field of biomechanics (Pataky et al., 2008, Pataky et al., 2013, Robinson et al., 2014). SPM recognizes regions of the waveforms which significantly differ between groups or conditions of interest. For detailed mathematical description of SPM, see (Pataky, 2010, Pataky, 2011). In brief, SPM was calculated as follows (Pataky et al., 2013):

$$
S P M\left\{T^{2}\right\} \square T^{2}\{q\}=J \times \bar{y}(q)^{T} \times W(q)^{(-1)} \times \bar{y}(q)
$$

Where:

$$
W(q)=\frac{1}{J-1}\left(\sum_{j=1}^{J}\left(y_{j}(q)-\bar{y}(q)\right) \times\left(y_{j}(q)-\bar{y}(q)\right)^{T}\right)
$$

In the above equations, $J$ is the number of vector components (equals to 100 samples for this study), $\bar{y}(q)$ is the mean vector field, and $W$ is the covariance matrix representing the variance-within and correlationbetween vector components across $J=100$ samples. SPM calculated the t-statistic as a function of time $(\operatorname{SPM}(\mathrm{t}))$. A critical statistical threshold $\left(\mathrm{t}^{*}\right)$ was determined based on the vector-field smoothness and temporal gradients of the waveforms. Regions of muscle or joint forces for which SPM(t) exceeded the critical threshold, were considered as statistically significant differences. The probability that the supra-threshold occurred by chance was calculated according to the random filed behavior of the vector to maintain the error rate of $\alpha=0.05$. Such statistical differences implied as muscular compensations in response to a weakened "muscle group". All of the aforementioned computations were conducted using "SPM1D", a free and open source software package for SPM (available at www.tpataky.net/spm1d).

\subsection{Principal component analysis (PCA)}

The sensitivity of joint force components due to individual muscle impairments were quantified by means of PCA (Fitzpatrick et al., 2011). As mentioned before, weakness of each muscle group was simulated with 200 probabilistic trials in which individual muscle strength variables $\left(F_{0}\right)$ were reduced simultaneously. For each 
probabilistic trial, the perturbed individual muscles were arranged as the input matrix and the resultant joint forces were arranged as the output matrix. PCA was then conducted on the input and output matrices to calculate Principal components (PCs). Each PC was a weighted combination of original variables (Jolliffe, 2002). The first four PCs of input matrix (output matrix) were summed to represent the overall input (output) PC ( $P C_{i}$ and $\left.P C_{o}\right)$ which explained $83-92 \%$ of the variation in the input and output datasets. The Pearson correlation coefficients were computed between $P C_{i}$ and $P C_{o}$ over the 200 probabilistic trials and were averaged over the entire gait cycle resulting in correlation indices. Each correlation index was then corrected with the contribution of an input (output) variable to the $P C_{i}\left(P C_{o}\right)$ resulting in the sensitivity index $(S I)$ of the output variable to a certain input variable. A probabilistic trial of the hip extensor weakness for example, was modeled as (for muscle abbreviation see Table 1):

$$
\begin{aligned}
& \text { Input }=[G M A X, G M E D, G M I N, A D D M, \text { PIRI, SEMIM, SEMIT, BFI }] ; \\
& \text { Output }=\left[H F_{x}, H F_{y}, H F_{z}, K F_{x}, K F_{y}, K F_{z}, A F_{x}, A F_{y}, A F_{z}\right]
\end{aligned}
$$

Where $H F_{x}, K F_{x}$ and $A F_{x}$ represent medial-lateral, $H F_{y}, K F_{y}$ and $A F_{y}$ represent anterior-posterior and $H F_{z}$, $K F_{z}$ and $A F_{z}$ represent axial components of hip, knee and ankle joint forces respectively. Input and output PCs were then calculated as:

$$
P C_{i 1}=\alpha_{1} G M A X+\beta_{1} G M E D+\ldots \ldots+\xi_{1} B F I
$$

$$
P C_{o 1}=a_{1} H F_{x}+b_{1} H F_{y}+\ldots \ldots+l_{1} A F_{z}
$$

Where $P C_{i l}\left(P C_{o l}\right)$ demonstrate the first mode of variations in the input (output) datasets. The overall input (output) PC was defined as the sum of the first four PCs:

$$
\begin{aligned}
& P C_{i}=P C_{i 1}+P C_{i 2}+P C_{i 3}+P C_{i 4} \\
& P C_{o}=P C_{o 1}+P C_{o 2}+P C_{o 3}+P C_{o 4}
\end{aligned}
$$

The sensitivity of anterior-posterior hip force due to gluteus maximus weakness was then computed as:

$$
S I_{G M A X}^{H F y}=\bar{\alpha} \times \operatorname{corr}\left(P C_{i}, P C_{o}\right) \times \bar{b}
$$

Where $\bar{\alpha}$ and $\bar{b}$ are the average contribution of GMAX and $H F_{y}$ in the $P C_{i}$ and $P C_{o}$. 


\section{Results}

Knee joint forces and muscle forces, computed from baseline MBD simulations, were compared to in vivo knee forces, measured by instrumented knee prostheses (Figure 2a) and with muscle forces estimated from experimental EMG reported in the Grand Challenge Data Repository (Figure 2b). Gait phases were described following established conventions (Perry and Davids, 1992). Good agreements in the overall patterns, timing and magnitudes built confidence in the resultant findings.

\subsection{Minimum requirements}

The minimum strength requirements to preserve the baseline TKA gait pattern were different for various muscle groups. In the hip, extensor, abductor and adductor muscles required $65 \%, 60 \%$ and $46 \%$ of their baseline strengths respectively. In the knee, extensor and flexor muscles required 50\% and $42 \%$ of their baseline strengths whilst ankle plantar flexor and dorsi-flexor muscles demanded $40 \%$ and $25 \%$ of their baseline strengths respectively.

\subsection{Compensatory mechanisms}

Table 2 lists the muscles which generated significantly $(\mathrm{p}<0.05)$ larger forces in response to the weakness of a certain muscle group (i.e. compensatory mechanisms). Results showed that hip extensor weakness led to an average increase of $48 \%$ at the magnitudes of hip flexor (i.e. SAR, ADDL, ADDB, ILIAC, PEC and TFL) muscle forces and an average increase of $27 \%$ at the magnitudes of ankle plantar flexor (i.e. SOL, GAS and TP) muscle forces (Figure 3). Hip flexor weakness was compensated by a significant increase in the hip extensor (i.e. ADDM, GMED, GMIN, SEMIM and SEMIT), ankle plantar flexor (i.e. GAS, SOL and FHL) and to a lesser extent by hip adductor muscle forces (i.e. OBE and QF) (Figure 4). Hip abductor weakness was balanced by remarkable contribution of hip flexor (i.e. ADDL, GRAC, ILIAC, SAR and RF) and knee flexor (i.e. BFsh, POP, SEMIT and GAS) muscles (Figure 5) whilst hip adductor weakness was compensated by knee flexor and hip abductor (i.e. GMED, OBI) muscles (Figure 6).

Knee extensor weakness was compensated by an average increase of $62 \%$ at the magnitudes of hip extensor (i.e. ADDM, GMAX, GMED, GMIN and BFsh) and an average increase of $48 \%$ at the magnitudes of hip flexor (ADDB, ADDL, ILIAC and PEC) muscle forces whilst knee flexor weakness was compensated by significant $(\mathrm{p}<0.05)$ contribution of hip flexor, hip extensor and to a lesser extent by ankle plantar flexor muscles (Appendix, Figures A.1-A.2). Ankle plantar flexor weakness was compensated by an average increase of $14 \%$ at the magnitudes of knee extensor (i.e. VAS, RF, and TFL), an average increase of $21 \%$ at the magnitudes of knee 
flexor (i.e. BFl, SEMIM, SEMIT, SAR, POP and GRAC) and an average increase of $20 \%$ at the magnitudes of hip adductor (i.e. ADDL, OBE and QF ) muscle forces (Appendix, Figure A.3). Ankle dorsi-flexor weakness was compensated by knee flexor, ankle plantar flexor and to a lesser extent by hip flexor and extensor muscles (Appendix, Figures A.4).

\subsection{Sensitivity analysis}

As expected, muscular compensations significantly influenced joint forces (Figure 7). Results are summarized in Table 3. Figure 8 reports the sensitivity of every joint force component due to the weakness of individual muscles. Muscles that span the hip (e.g. GMAX, ILIAC and BF) and those that do not span the hip joint (e.g. VAS, SOL and GAS) substantially affected the hip joint force. Hip joint force was more sensitive to the weakness of hip and knee extensor $(S I=51 \%)$ and hip abductor $(S I=47 \%)$ muscles. Knee joint force was slightly more sensitive to the weakness of those muscles that span the knee (e.g. SEMIM, SEMIT, BF, RF, VAS and TFL) rather than muscles that do not span the knee joint (e.g. GAS, SOL and TA) . Of these muscles, bi-articular muscles that span both knee and hip joints had a greater impact on the knee joint force (i.e. SEMIM, SEMIT, BF and RF). Knee joint force was mostly sensitive to the weakness of the knee extensor ( $S I=61 \%)$, knee flexor $(S I=56 \%)$ and hip extensor $(S I=48 \%)$ muscles. Ankle force was more sensitive to the weakness of ankle plantar flexor $(S I=44 \%)$ than to the weakness of ankle dorsi-flexor $(S I=35 \%)$ muscles. Ankle force was noticeably influenced by weakness of GAS $(S I=63 \%)$, SOL $(S I=57 \%)$ and TA $(S I=44 \%)$ muscles.

\section{Discussion}

The abnormal gait characteristics of TKA patients, compared to non-injured counterparts, have been well studied (Alnahdi et al., 2011, Hatfield et al., 2011, McClelland et al., 2011, Yoshida et al., 2012). Despite, little is known about how vulnerable such an abnormal gait might be due to lower extremity muscle impairment. The main aim of this study was to quantify the muscular compensations and joint force perturbations in response to muscle impairments in TKA patients. Technical contribution of this study can be highlighted in terms of SPM and PCA. Conventional statistical analyses such as t-test or ANOVA are widely applied in the field of gait analysis. These tests however necessitate extracting certain scalars from the original pattern at discrete time points, typically maximum and minimum values (Goldberg and Neptune, 2007, Butler et al., Jonkers et al., 2003, Valente et al., 2013, Klemetti et al., 2014, Thompson et al., 2013, van der Krogt et al., 2012). Hence, scalar-based hypotheses oversimplify the underlying dynamics of original waveforms. In the present study, SPM analysis was used as an alternative to broaden the scope of our statistical comparisons to the entire gait cycle. On the other hand, each muscle group is consisted of several individual muscles which work inter-dependently to dictate joint force patterns. Joint forces are in turn highly inter-connected. Traditional scenario of sensitivity analysis is inherently unable to account for any sort of interactions within inputs or outputs (Fitzpatrick et al., 2011). PCA 
technique can be used instead to address such interactions(Ardestani et al., 2015b, Ardestani et al., 2015a, Ardestani et al., 2015c).

In terms of insights, previous attempts addressed the muscular compensations in response to the weakness of one or several muscles for non-injured subjects by simulating discrete levels of impairments(Jonkers et al., 2003, Steele et al., 2012, Thompson et al., 2013). To the best of authors' knowledge, Valente et al. (2013) is the only study in which hip abductor muscle impairment was simulated by means of probabilistic analysis. The present study is perhaps the first one to provide a comprehensive evaluation of muscular compensations in TKA patients. Overall, present findings are consistent with available literature; e.g. hip extensor compensated for hip flexor weakness whilst hip extensor (i.e. ADDM and GMAX) and hip flexor (i.e. ADDB and ILIAC) addressed the knee extensor weakness(Goldberg and Neptune, 2007, van der Krogt et al., 2012). Parts of the present findings however, have not been observed in non-injured subjects suggesting that muscle weakness in TKA patients likely require more involvement of other muscles to be compensated. For example, present findings suggested that in TKA patients, hip adductor and ankle planter flexor muscles accompanied hip extensor to compensate hip flexor weakness. As another example, other hip extensor (i.e. ADDM, GMAX, GMED, GMIN and BFsh) and hip flexor (i.e. ADDB, ADDL, ILIAC and PEC) muscles worked together to address knee extensor weakness in TKA patients.

Present findings also suggested that TKA patients might not tolerate muscle strength deficits as much as non-injured counterparts. While a minimum strength of $60 \%$ for hip extensor/flexor/abductor, and $35 \%$ for ankle plantar flexor muscles suffice to preserve the baseline gait pattern in non-injured subjects (van der Krogt et al., 2012), TKA patients demanded higher strength (65\% of the nominal values for hip muscles and $40 \%$ for ankle plantar flexor muscles) to preserve their baseline gait patterns. Considering the fact that TKA patients often suffer from weak quadriceps and hamstring, higher muscle strength requirements in this cohort may be understandable. The aforementioned findings are of significant importance for rehabilitation purposes. From this perspective, muscles that may induce severe compensations in other muscles, or those muscle groups capable of compensating for hamstring and quadriceps weakness, may be targeted for future rehabilitation.

There were several limitations in this study, but perhaps the main one was that, the geometry of knee implant was not included in the MBD analysis. In fact TKA-specific information was exclusively included by means of kinematic and GRF data. One previous study extended a rigid MBD simulation of the present musculoskeletal model to incorporate the bearing surface geometry of the knee implant as well as the flexible contact mechanics of the tibiofemoral and patellofemoral joints(Chen et al., 2014). Although the model achieved an acceptable accuracy to calculate contact forces, the computational time increased remarkably. Hence the model was impractical for the present study which required large iterations of probabilistic MBD analysis. Moreover, the 
primary aim of the present study was to elicit significant "differences" between the baseline and impaired simulations. Since both baseline and impaired simulations were conducted using the same model, and considering that predicted knee joint forces were well consistent with the in vivo measurements, it is likely that this simplification had a minimal impact on our findings. Another key limitation of this study was small number of patients. Considering the large inter-subject variability in soft tissue and patients' musculature, larger number of patients are required to confirm the findings of this study. Nevertheless, the developed framework is equally applicable.

\section{Conclusion}

A probabilistic MBD analysis, combined with SPM and PCA analyses, were used to evaluate the minimum strength requirements of muscles and muscular compensatory mechanisms in TKA patients. Our findings suggested that: (1) hip flexor and ankle plantar flexor muscles compensated for hip extensor weakness; (2) hip extensor, hip adductor and ankle plantar flexor muscles compensated for hip flexor weakness; (3) hip and knee flexor muscles responded to hip abductor weakness;(4) knee flexor and hip abductor balanced hip adductor impairment; and (5) knee extensor and knee flexor weakness were compensated by hip extensor and hip flexor muscles. While knee joint force was more sensitive to the bi-articular spanning muscles that cross both hip and knee joints, hip force was fairly sensitive to both hip-spanning and non hip-spanning muscles.

\section{Conflict of interest statement}

The authors have no conflict of interests to be declared.

\section{Acknowledgments}

This work was supported by Chinese Scholarship Council (number 2012GXZI23) and the program of

Xi'an Jiao Tong University [grant number xjj2012108]. The authors gratefully acknowledge " Grand Challenge

Competition to Predict In Vivo Knee Loads" for releasing the experimental data. We would also like to appreciate Professor Todd Pataky from Shinshu University (Japan) for his guidance on spatial parameter mapping technique.

\section{Reference}

ALI, N., ANDERSEN, M. S., RASMUSSEN, J., ROBERTSON, D. G. E. \& ROUHI, G. 2013. The application of musculoskeletal modeling to investigate gender bias in non-contact ACL injury rate during single-leg landings. Computer Methods in Biomechanics and Biomedical Engineering, 17, 1602-1616.

ALNAHDI, A. H., ZENI, J. A. \& SNYDER-MACKLER, L. 2011. Gait after unilateral total knee arthroplasty: Frontal plane analysis. Journal of Orthopaedic Research, 29, 647-652.

ANDRIACCHI, T. P. 1993. Functional analysis of pre and post-knee surgery: total knee arthroplasty and ACL reconstruction. Journal of biomechanical engineering, 115, 575-581.

ARDESTANI, M. M., MOAZEN, M. \& JIN, Z. 2015a. Contribution of geometric design parameters to knee implant performance: Conflicting impact of conformity on kinematics and contact mechanics. The Knee, in press. 
ARDESTANI, M. M., MOAZEN, M. \& JIN, Z. 2015b. Sensitivity analysis of human lower extremity joint moments due to changes in joint kinematics. Medical Engineering \& Physics, 37, 165-174.

ARDESTANI, M. M., MOAZEN, M., MANIEI, E. \& JIN, Z. 2015c. Posterior stabilized versus cruciate retaining total knee arthroplasty designs: Conformity affects the performance reliability of the design over the patient population. Medical Engineering \& Physics, in press.

BENEDETTI, M. G., CATANI, F., BILOTTA, T. W., MARCACCI, M., MARIANI, E. \& GIANNINI, S. 2003. Muscle activation pattern and gait biomechanics after total knee replacement. Clinical Biomechanics, 18, 871-876.

BJERKE, J., ÖHBERG, F., NILSSON, K. G. \& STENSDOTTER, A. K. 2014. Compensatory Strategies for Muscle Weakness During Stair Ascent in Subjects With Total Knee Arthroplasty. The Journal of Arthroplasty, 29, 14991502 .

BUTLER, R. J., RUBERTE THIELE, R. A., BARNES, C. L., BOLOGNESI, M. P. \& QUEEN, R. M. Unipedal Balance Is Affected by Lower Extremity Joint Arthroplasty Procedure 1 Year Following Surgery. The Journal of Arthroplasty.

CHEN, Z., ZHANG, X., ARDESTANI, M. M., WANG, L., LIU, Y., LIAN, Q., HE, J., LI, D. \& JIN, Z. 2014. Prediction of in vivo joint mechanics of an artificial knee implant using rigid multi-body dynamics with elastic contacts. Proceedings of the Institution of Mechanical Engineers, Part H: Journal of Engineering in Medicine, 228, 564-575.

DA SILVA, R. R., SANTOS, A. A. M., DE SAMPAIO CARVALHO JÚNIOR, J. \& MATOS, M. A. 2014. Quality of life after total knee arthroplasty: systematic review()(). Revista Brasileira de Ortopedia, 49, 520-527.

DAMSGAARD, M., RASMUSSEN, J., CHRISTENSEN, S. T., SURMA, E. \& DE ZEE, M. 2006. Analysis of musculoskeletal systems in the AnyBody Modeling System. Simulation Modelling Practice and Theory, 14, 11001111.

DAVIDSON, B. S., JUDD, D. L., THOMAS, A. C., MIZNER, R. L., ECKHOFF, D. G. \& STEVENS-LAPSLEY, J. E. 2013. Muscle activation and coactivation during five-time-sit-to-stand movement in patients undergoing total knee arthroplasty. Journal of Electromyography and Kinesiology, 23, 1485-1493.

FARQUHAR, S. J., KAUFMAN, K. R. \& SNYDER-MACKLER, L. 2009. Sit-to-Stand 3 months after unilateral total knee arthroplasty: Comparison of self-selected and constrained conditions. Gait \& Posture, 30, 187-191.

FITZPATRICK, C. K., BALDWIN, M. A., RULLKOETTER, P. J. \& LAZ, P. J. 2011. Combined probabilistic and principal component analysis approach for multivariate sensitivity evaluation and application to implanted patellofemoral mechanics. Journal of biomechanics, 44, 13-21.

FREGLY, B. J., BESIER, T. F., LLOYD, D. G., DELP, S. L., BANKS, S. A., PANDY, M. G. \& D'LIMA, D. D. 2012. Grand challenge competition to predict in vivo knee loads. Journal of Orthopaedic Research, 30, 503-513.

FRISTON, K. J., HOLMES, A. P., WORSLEY, K. J., POLINE, J., FRITH, C. D. \& FRACKOWIAK, R. S. 1994. Statistical parametric maps in functional imaging: a general linear approach. Human brain mapping, 2, 189-210.

GOLDBERG, E. J. \& NEPTUNE, R. R. 2007. Compensatory strategies during normal walking in response to muscle weakness and increased hip joint stiffness. Gait \& Posture, 25, 360-367.

HATFIELD, G. L., HUBLEY-KOZEY, C. L., ASTEPHEN WILSON, J. L. \& DUNBAR, M. J. 2011. The Effect of Total Knee Arthroplasty on Knee Joint Kinematics and Kinetics During Gait. The Journal of Arthroplasty, 26, 309-318.

IMAN, R. L. 2008. Latin hypercube sampling, Wiley Online Library.

JARIC, S. 2002. Muscle strength testing: use of normalisation for body size. Sports Medicine, 32, 615-631.

JOLLIFFE, I. 2002. Principal component analysis, Wiley Online Library.

JONKERS, I., STEWART, C. \& SPAEPEN, A. 2003. The complementary role of the plantarflexors, hamstrings and gluteus maximus in the control of stance limb stability during gait. Gait \& Posture, 17, 264-272.

JUDD, D. L., ECKHOFF, D. G. \& STEVENS-LAPSLEY, J. E. 2012. Muscle Strength Loss in the Lower Limb After Total Knee Arthroplasty. American Journal of Physical Medicine \& Rehabilitation, 91, 220-230 10.1097/PHM.0b013e3182411e49.

KINNEY, A. L., BESIER, T. F., D'LIMA, D. D. \& FREGLY, B. J. 2013. Update on Grand Challenge Competition to Predict in Vivo Knee Loads. Journal of Biomechanical Engineering, 135, 021012-021012.

KLEIN HORSMAN, M. D. 2007. The Twente lower extremity model: consistent dynamic simulation of the human locomotor apparatus, University of Twente.

KLEMETTI, R., STEELE, K. M., MOILANEN, P., AVELA, J. \& TIMONEN, J. 2014. Contributions of individual muscles to the sagittal- and frontal-plane angular accelerations of the trunk in walking. Journal of Biomechanics, 47, 22632268.

KNARR, B. A., REISMAN, D. S., BINDER-MACLEOD, S. A. \& HIGGINSON, J. S. 2013. Understanding compensatory strategies for muscle weakness during gait by simulating activation deficits seen post-stroke. Gait \& Posture, 38, 270-275.

MCCLELlAND, J. A., WEBSTER, K. E., FELLER, J. A. \& MENZ, H. B. 2010. Knee kinetics during walking at different speeds in people who have undergone total knee replacement. Gait \& Posture, 32, 205-210. 
MCClElland, J. A., WEBSTER, K. E., FELLER, J. A. \& MENZ, H. B. 2011. Knee kinematics during walking at different speeds in people who have undergone total knee replacement. The Knee, 18, 151-155.

OUELLET, D. \& MOFFET, H. 2002. Locomotor deficits before and two months after knee arthroplasty. Arthritis Care \& Research, 47, 484-493.

PATAKY, T. C. 2010. Generalized n-dimensional biomechanical field analysis using statistical parametric mapping. Journal of biomechanics, 43, 1976-1982.

PATAKY, T. C. 2011. One-dimensional statistical parametric mapping in Python. Computer Methods in Biomechanics and Biomedical Engineering, 15, 295-301.

PATAKY, T. C., CARAVAGGI, P., SAVAGE, R., PARKER, D., GOULERMAS, J. Y., SELLERS, W. I. \& CROMPTON, R. H. 2008. New insights into the plantar pressure correlates of walking speed using pedobarographic statistical parametric mapping (pSPM). Journal of Biomechanics, 41, 1987-1994.

PATAKY, T. C., ROBINSON, M. A. \& VANRENTERGHEM, J. 2013. Vector field statistical analysis of kinematic and force trajectories. Journal of Biomechanics, 46, 2394-2401.

PERRY, J. \& DAVIDS, J. R. 1992. Gait analysis: normal and pathological function. Journal of Pediatric Orthopaedics, 12, 815.

RASMUSSEN, J., DAMSGAARD, M. \& VOIGT, M. 2001. Muscle recruitment by the $\min / \mathrm{max}$ criterion - a comparative numerical study. Journal of Biomechanics, 34, 409-415.

ROBINSON, M. A., VANRENTERGHEM, J. \& PATAKY, T. C. 2014. Statistical Parametric Mapping (SPM) for alphabased statistical analyses of multi-muscle EMG time-series. Journal of Electromyography and Kinesiology, in press.

SCHACHE, M. B., MCCLELLAND, J. A. \& WEBSTER, K. E. 2014. Lower limb strength following total knee arthroplasty: A systematic review. The Knee, 21, 12-20.

STEELE, K. M., VAN DER KROGT, M. M., SCHWARTZ, M. H. \& DELP, S. L. 2012. How much muscle strength is required to walk in a crouch gait? Journal of Biomechanics, 45, 2564-2569.

STEVENS-LAPSLEY, J., BALTER, J., KOHRT, W. \& ECKHOFF, D. 2010. Quadriceps and Hamstrings Muscle Dysfunction after Total Knee Arthroplasty. Clinical Orthopaedics and Related Research®, 468, 2460-2468.

THOMAS, A. C., JUDD, D. L., DAVIDSON, B. S., ECKHOFF, D. G. \& STEVENS-LAPSLEY, J. E. 2014. Quadriceps/hamstrings co-activation increases early after total knee arthroplasty. The Knee.

THOMPSON, J. A., CHAUDHARI, A. M. W., SCHMITT, L. C., BEST, T. M. \& SISTON, R. A. 2013. Gluteus maximus and soleus compensate for simulated quadriceps atrophy and activation failure during walking. Journal of Biomechanics, 46, $2165-2172$.

VALENTE, G., TADDEI, F. \& JONKERS, I. 2013. Influence of weak hip abductor muscles on joint contact forces during normal walking: probabilistic modeling analysis. Journal of Biomechanics, 46, 2186-2193.

VAN DER KROGT, M. M., DELP, S. L. \& SCHWARTZ, M. H. 2012. How robust is human gait to muscle weakness? Gait \& Posture, 36, 113-119.

WORSLEY, P., STOKES, M. \& TAYLOR, M. 2011. Predicted knee kinematics and kinetics during functional activities using motion capture and musculoskeletal modelling in healthy older people. Gait \& Posture, 33, 268-273.

YERCAN, H. S., AIT SI SELMI, T., SUGUN, T. S. \& NEYRET, P. 2005. Tibiofemoral instability in primary total knee replacement: A review, Part 1: Basic principles and classification. The Knee, 12, 257-266.

YOSHIDA, Y., MIZNER, R. L. \& SNYDER-MACKLER, L. 2013. Association between long-term quadriceps weakness and early walking muscle co-contraction after total knee arthroplasty. The Knee, 20, 426-431.

YOSHIDA, Y., ZENI, J. \& SNYDER-MACKLER, J. L. 2012. Do Patients Achieve Normal Gait Patterns 3 Years After Total Knee Arthroplasty? Journal of Orthopaedic \& Sports Physical Therapy, 42, 1039-1049. 
Figure
Click here to download Figure: Figure 1.docx

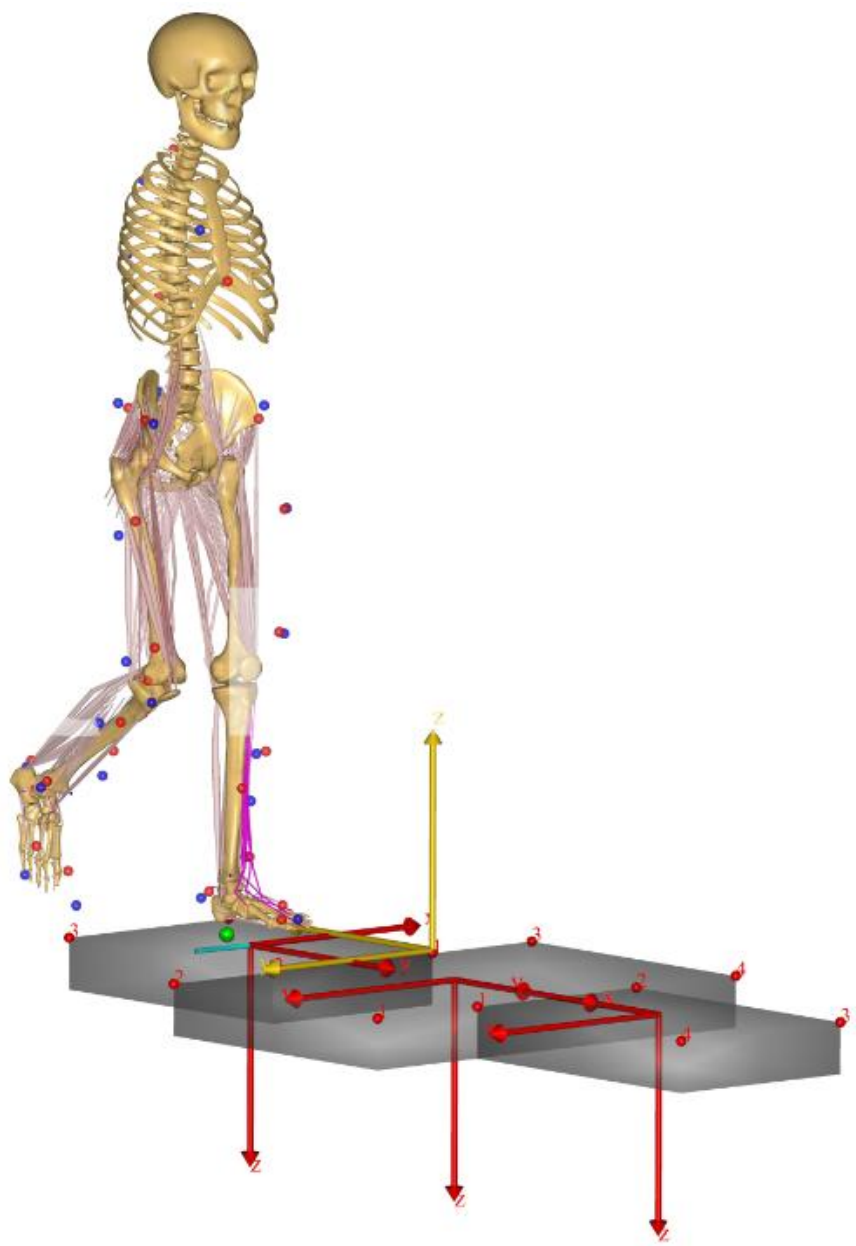

Figure 1 Musculoskeletal model based on TLEM 

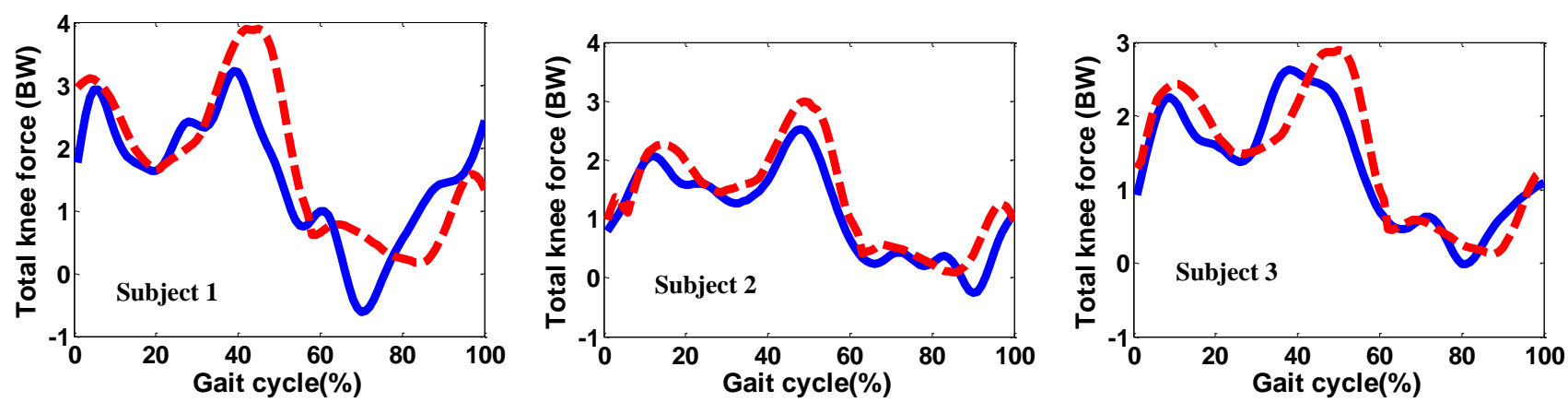

(a)
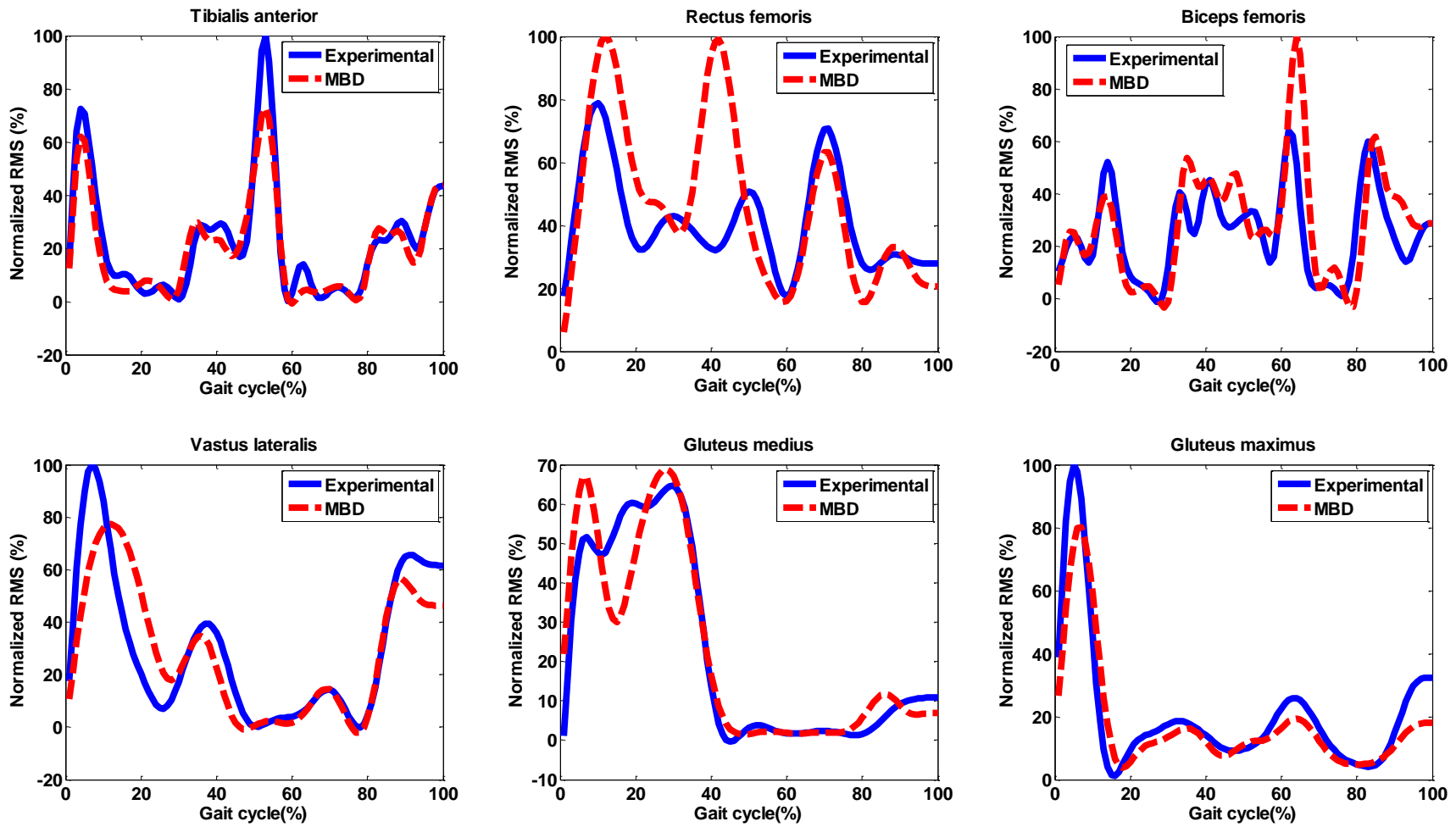

(b)

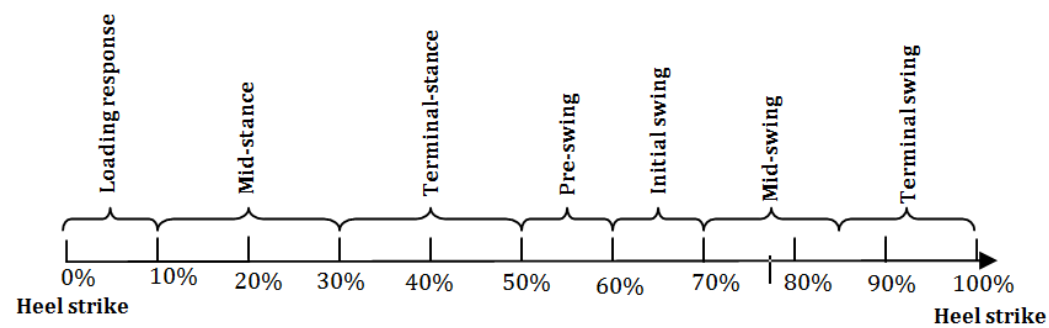

Figure 2 (a) In vivo measurements of knee force (solid line) versus MBD computations (dashed line) for three subjects of repository;

(b) root mean square (RMS) of experimentally-measured muscle activities (solid line) versus MBD computations (dashed line) averaged over six subjects. 

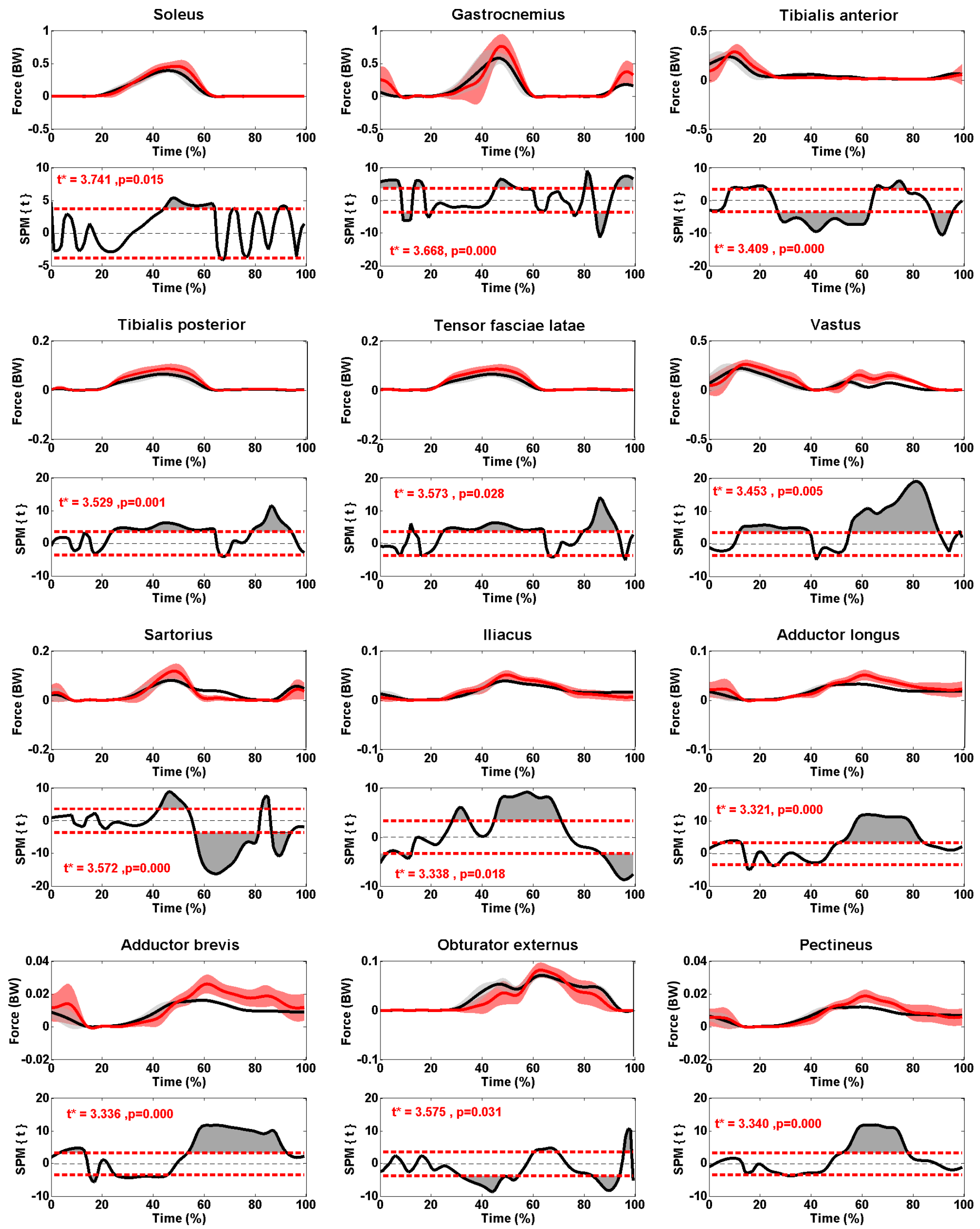

Figure 3 Mean (black solid line) and standard deviation (gray cloud) of muscle forces from baseline simulations versus mean (red solid) and standard deviation (red cloud) of "impaired-hip-extensor simulations". Regions of gait cycle where SPM (t) exceeds critical threshold demonstrates significant differences. The horizontal dotted line indicates the critical thresholds ( $\mathrm{t} *$ ). 

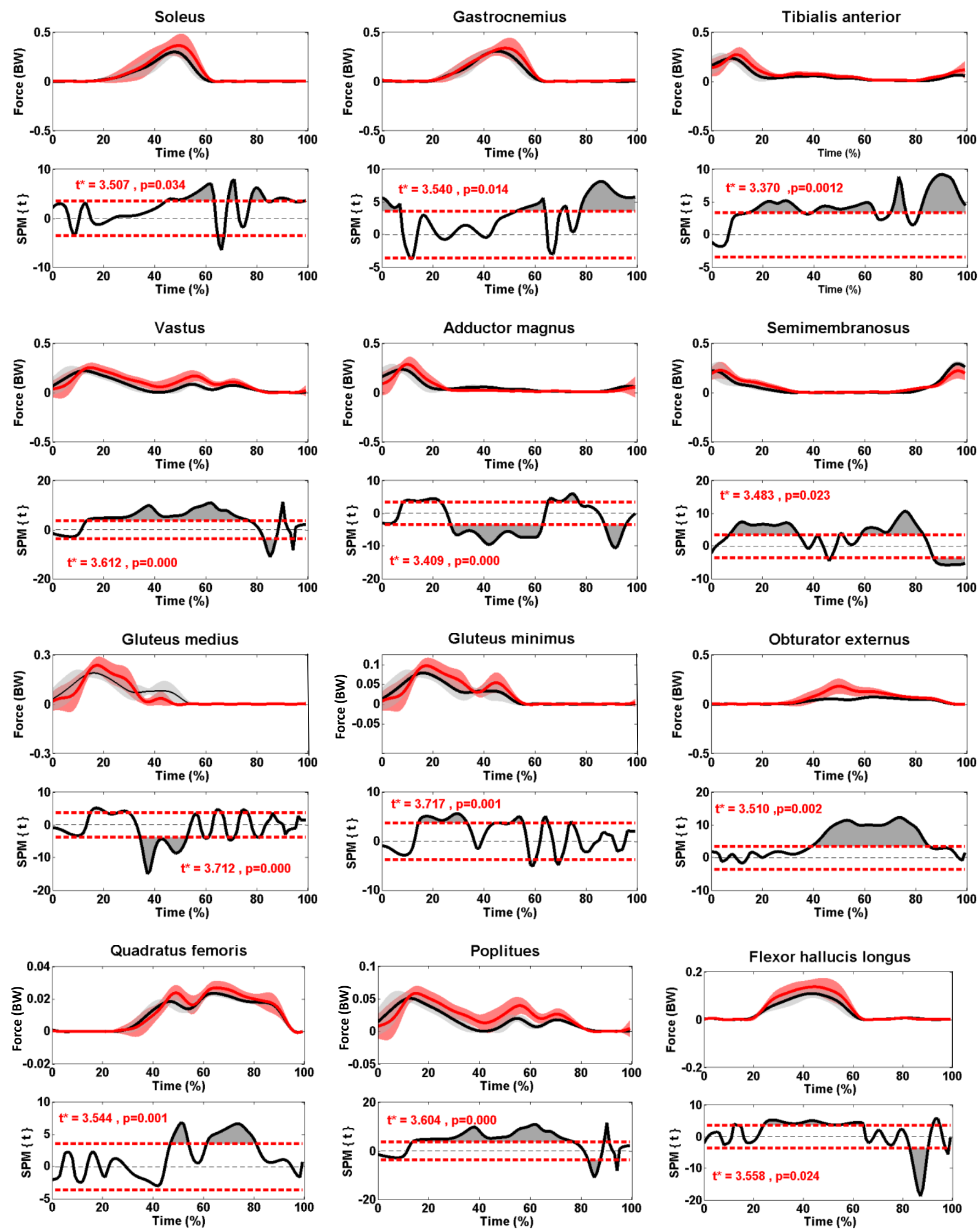

Figure 4 Mean (black solid line) and standard deviation (gray cloud) of muscle forces from baseline simulation versus mean (red solid) and standard deviation (red cloud ) of "impaired-hip-flexor simulations". Regions of gait cycle where SPM (t) exceeds critical threshold demonstrates significant differences. The horizontal dotted line indicates the critical thresholds $\left(\mathrm{t}^{*}\right)$. 

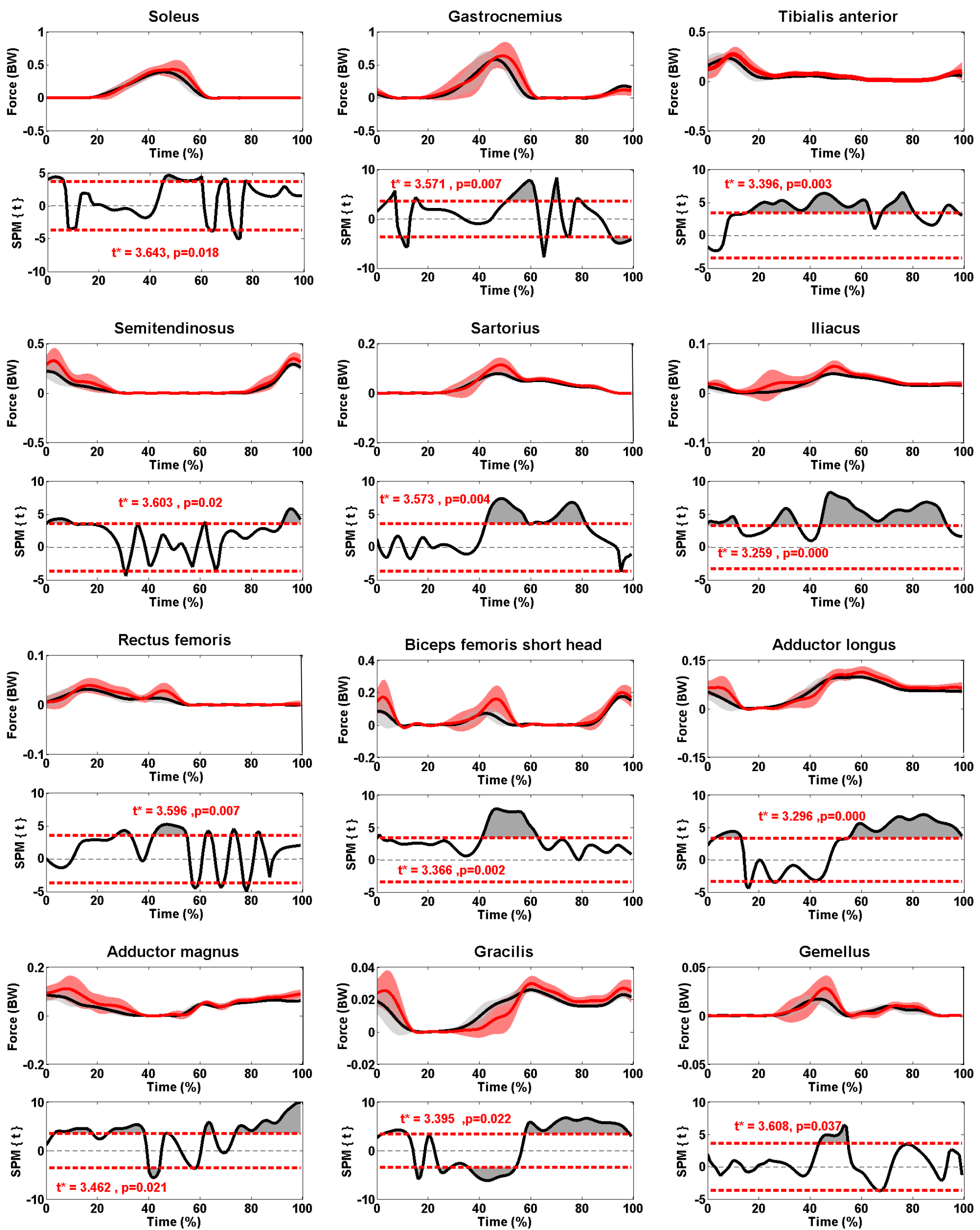

Figure 5 Mean (black solid line) and standard deviation (gray cloud) of muscle forces from baseline simulations versus mean (red solid) and standard deviation (red cloud) of "impaired-hip-abductor simulations". Regions of gait cycle where SPM (t) exceeds critical threshold demonstrates significant differences. The horizontal dotted line indicates the critical thresholds $\left(\mathrm{t}^{*}\right)$. 

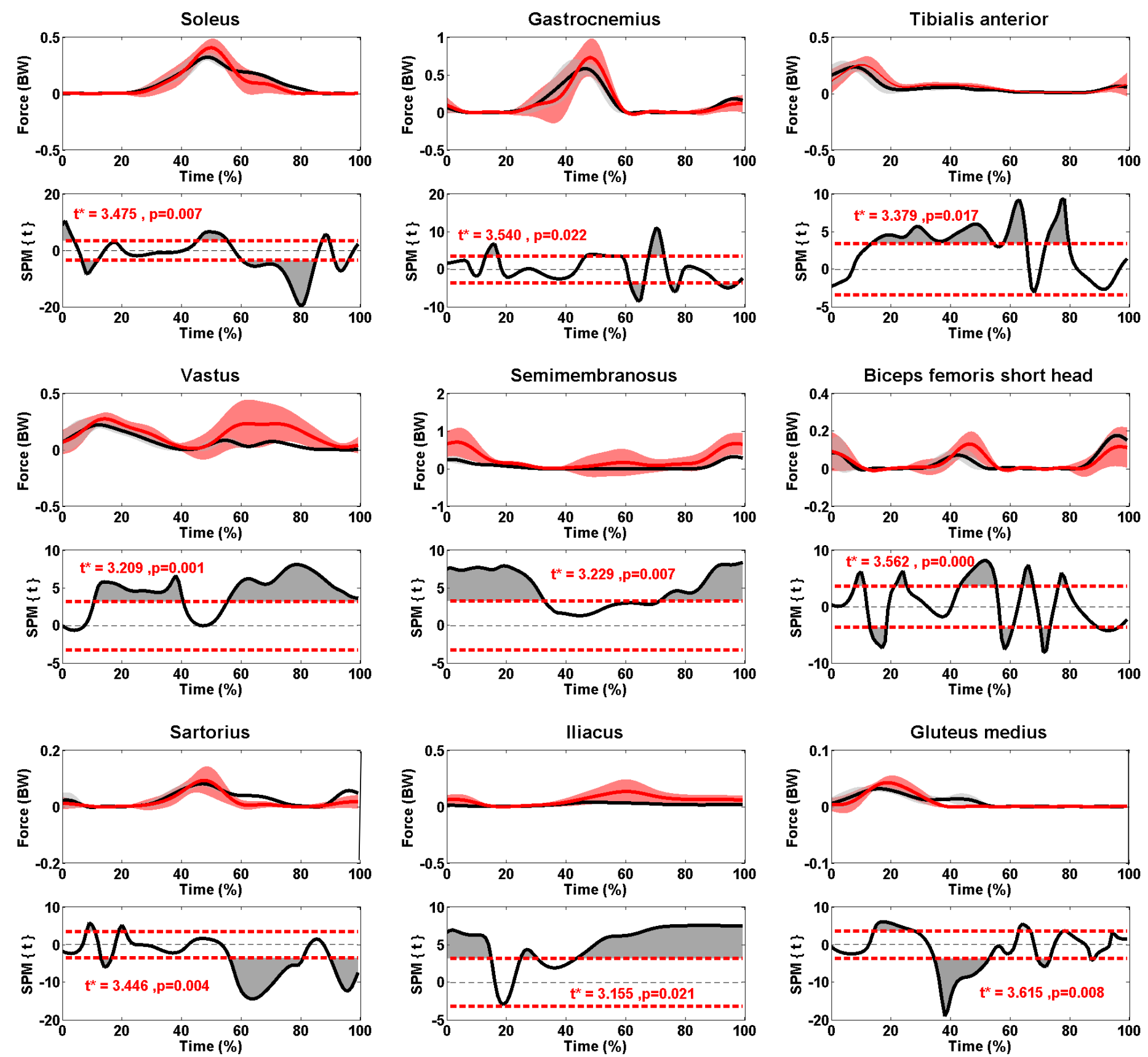

Figure 6 Mean (black solid line) and standard deviation (gray cloud) of muscle forces from baseline simulations versus mean (red solid) and standard deviation (red cloud) of "impaired-hip-adductor simulations". Regions of gait cycle where SPM (t) exceeds critical threshold demonstrates significant differences. The horizontal dotted line indicates the critical thresholds ( $\left.\mathrm{t}^{*}\right)$. 

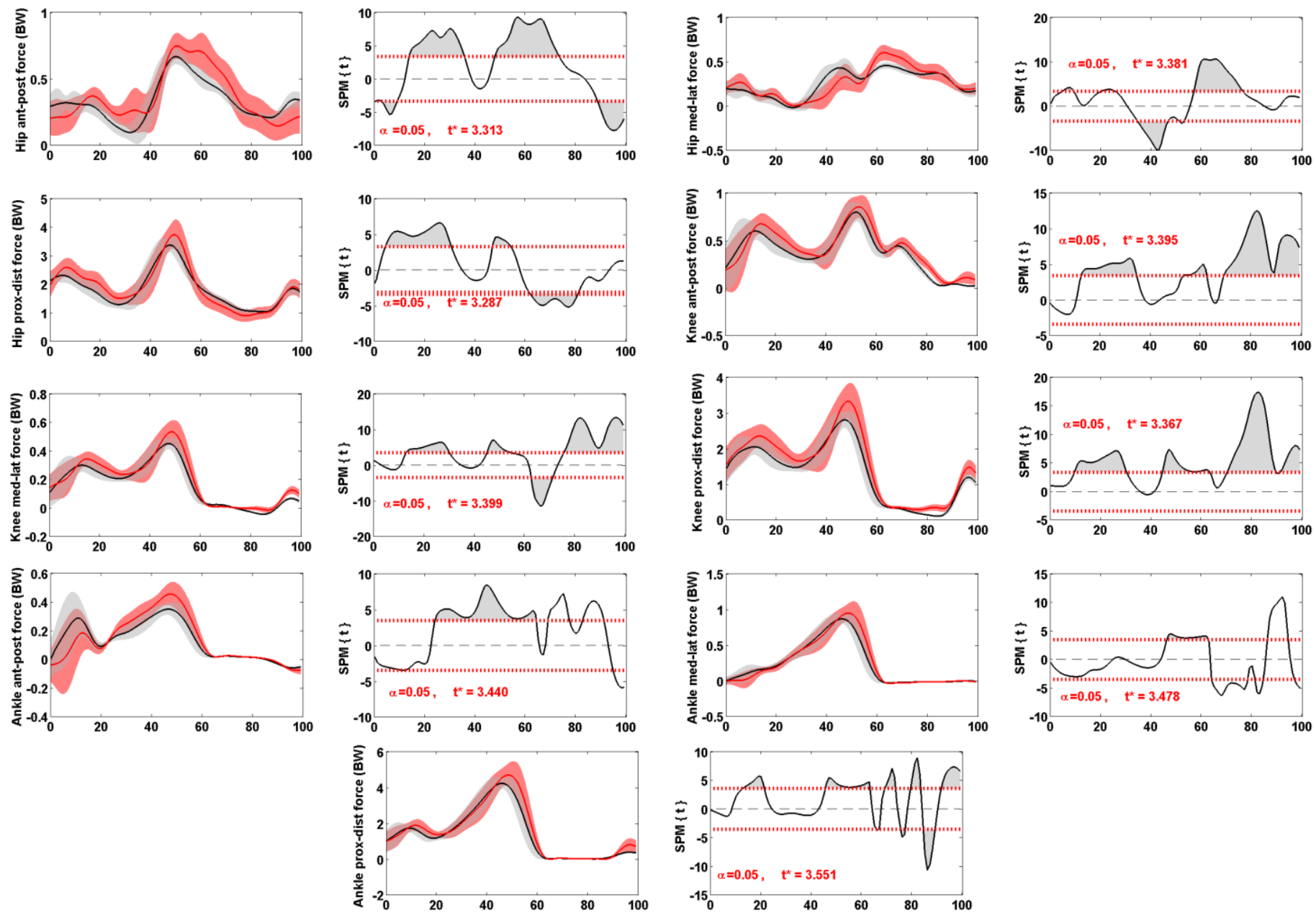

Figure 7 Mean (black solid line) and standard deviation (gray cloud) of joint forces from baseline simulations versus mean (red solid) and standard deviation (red cloud) of "impaired-hip-extensor" simulations. Regions of gait cycle where SPM (t) exceeds critical threshold demonstrates significant differences. The horizontal dotted line indicates the critical thresholds ( $\mathrm{t}^{*}$ ). 

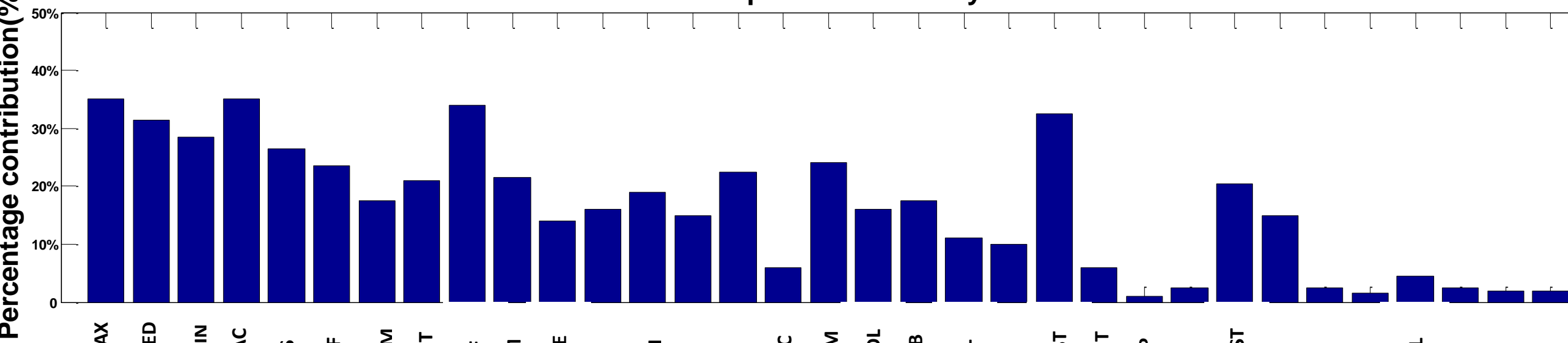

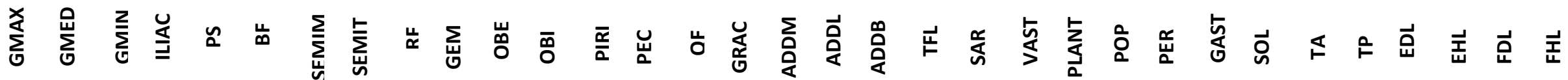

ㅇ

Knee force sensitivity

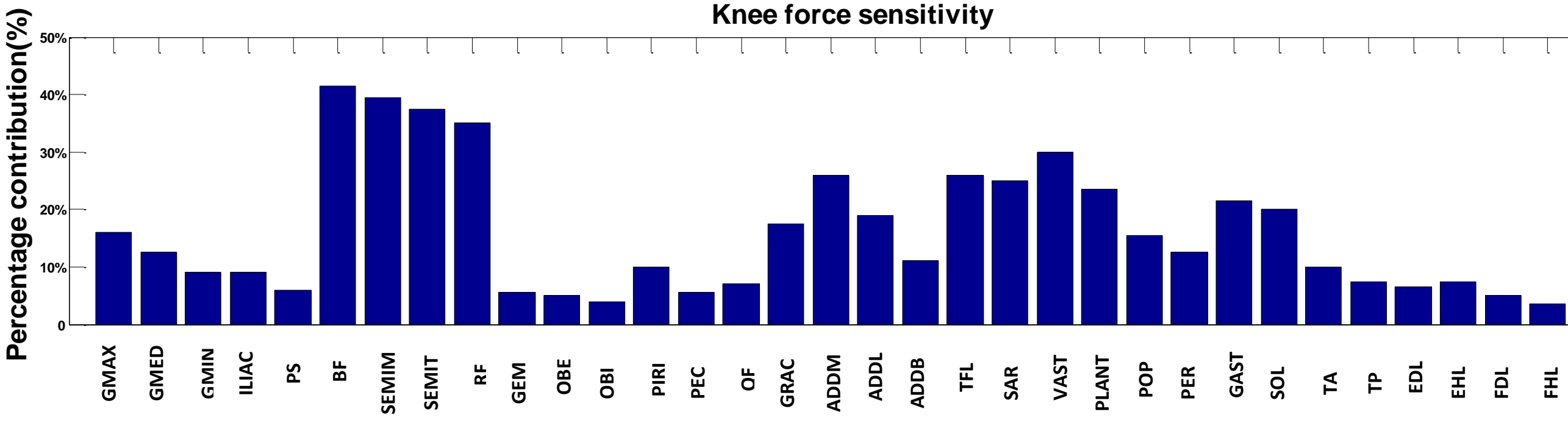


Table 1 Muscle groups and their individual muscles

\begin{tabular}{|c|c|}
\hline Muscle group & $\begin{array}{r}\text { Description of constituent individual muscles } \\
\end{array}$ \\
\hline Hip extensor & $\begin{array}{l}\text { Gluteus maximus (GMAX), Gluteus medius (GMED), Gluteus minimus } \\
\text { (GMIN), Adductor magnus (ADDM), Piriformis(PIRI), } \\
\text { Semimembranosus(SEMIM), Semitendinosus(SEMIT), Biceps femoris long } \\
\text { head(BFl) }\end{array}$ \\
\hline Hip flexor & $\begin{array}{l}\text { Iliacus (ILIAC), Psoas (PS), Tensor fasciae latae(TFL), Pectineus(PEC), } \\
\text { Adductor longus(ADDL), Adductor brevis(ADDB), Gracilis(GRAC), Rectus } \\
\text { femoris(RF), Sartorius (SAR) }\end{array}$ \\
\hline Hip abductor & $\begin{array}{l}\text { Gluteus medius (GMED), Gluteus maximus (GMAX), Gluteus minimus } \\
\text { (GMIN), Tensor fasciae latae(TFL), Piriformis(PIRI), Obturator internus(OBI) }\end{array}$ \\
\hline Hip adductor & $\begin{array}{l}\text { Adductor magnus (ADDM), Adductor longus(ADDL), Adductor brevis } \\
\text { (ADDB), Gluteus maximus (GMAX), Gracilis(GRAC), Pectineus(PEC), } \\
\text { Quadratus femoris(QF), Obturator externus (OBE), Semitendinosus(SEMIT) }\end{array}$ \\
\hline Knee extensor & Rectus femoris(RF), Vastus (VAS), Tensor fasciae latae(TFL) \\
\hline Knee flexor & $\begin{array}{l}\text { Semimembranosus(SEMIM), Semitendinosus(SEMIT), Biceps femoris long } \\
\text { head (BFl), Gracilis(GRAC), Sartorius (SAR), Popliteus(POP), Gastrocnemius } \\
\text { (GAS) }\end{array}$ \\
\hline Ankle dorsi-flexor & $\begin{array}{l}\text { Tibialis anterior(TA), Extensor digitorum longus(EDL), Extensor hallucis } \\
\text { longus(EHL) }\end{array}$ \\
\hline Ankle plantar-flexor & $\begin{array}{l}\text { Peroneus (PER), Flexor digitorum longus(FDL), Flexor hallucis longus(FHL), } \\
\text { Tibialis posterior(TP), Soleus(SOL), Gastrocnemius (GAS), Plantaris(PLANT) }\end{array}$ \\
\hline
\end{tabular}


Table 2 Muscular compensatory mechanisms in response to various muscle impairments. Percentage changes in the magnitudes of muscle forces are reported in terms of mean \pm standard deviation. Abbreviations are defined in Table 1.

\begin{tabular}{|c|c|c|c|c|c|c|c|c|}
\hline \multicolumn{9}{|c|}{ Impaired muscle groups } \\
\hline & $\begin{array}{c}\text { Hip } \\
\text { Extensor }\end{array}$ & Hip Flexor & $\begin{array}{c}\text { Hip } \\
\text { abductor }\end{array}$ & $\begin{array}{c}\text { Hip } \\
\text { adductor }\end{array}$ & Knee extensor & Knee flexor & $\begin{array}{l}\text { Ankle plantar- } \\
\text { flexor }\end{array}$ & Ankle dorsi -flexor \\
\hline GMAX & - & - & - & - & $105 \% \pm 85 \%$ & $74 \% \pm 78 \%$ & $8 \% \pm 28 \%$ & - \\
\hline GMED & - & $21 \% \pm 22 \%$ & - & $32 \% \pm 27 \%$ & $64 \% \pm 45 \%$ & $29 \% \pm 48 \%$ & $19 \% \pm 21 \%$ & $18 \% \pm 21 \%$ \\
\hline GMIN & - & $85 \% \pm 57 \%$ & - & - & $88 \% \pm 45 \%$ & $42 \% \pm 56 \%$ & - & $17 \% \pm 18 \%$ \\
\hline ADDM & - & $59 \% \pm 54 \%$ & $47 \% \pm 58 \%$ & - & $27 \% \pm 20 \%$ & $71 \% \pm 60 \%$ & - & $30 \% \pm 41 \%$ \\
\hline ADDL & $53 \% \pm 30 \%$ & - & $16 \% \pm 17 \%$ & - & $48 \% \pm 30 \%$ & $25 \% \pm 27 \%$ & $16 \% \pm 17 \%$ & - \\
\hline ADDB & $59 \% \pm 33 \%$ & - & - & - & $31 \% \pm 23 \%$ & $25 \% \pm 27 \%$ & - & - \\
\hline BF-sh & - & - & $31 \% \pm 25 \%$ & $11 \% \pm 29 \%$ & $26 \% \pm 26 \%$ & - & - & - \\
\hline BFL & - & - & - & - & - & - & $21 \% \pm 22 \%$ & $21 \% \pm 23 \%$ \\
\hline VAS & $12 \% \pm 18 \%$ & $10 \% \pm 17 \%$ & - & $44 \% \pm 53 \%$ & - & - & $10 \% \pm 17 \%$ & $10 \% \pm 17 \%$ \\
\hline SAR & $47 \% \pm 28 \%$ & - & $48 \% \pm 29 \%$ & $32 \% \pm 34 \%$ & - & - & $17 \% \pm 18 \%$ & $17 \% \pm 18 \%$ \\
\hline SOL & $16 \% \pm 21 \%$ & $21 \% \pm 20 \%$ & $15 \% \pm 21 \%$ & $18 \% \pm 20 \%$ & - & - & - & $20 \% \pm 21 \%$ \\
\hline $\mathbf{R F}$ & - & - & $36 \% \pm 22 \%$ & - & - & - & $16 \% \pm 17 \%$ & $15 \% \pm 17 \%$ \\
\hline TFL & $50 \% \pm 29 \%$ & - & - & - & - & - & $16 \% \pm 18 \%$ & $17 \% \pm 18 \%$ \\
\hline ILIAC & $30 \% \pm 23 \%$ & - & $46 \% \pm 39 \%$ & $250 \% \pm 27 \%$ & $66 \% \pm 35 \%$ & $33 \% \pm 38 \%$ & $17 \% \pm 20 \%$ & $17 \% \pm 20 \%$ \\
\hline GAS & $32 \% \pm 27 \%$ & $14 \% \pm 18 \%$ & $43 \% \pm 34 \%$ & $35 \% \pm 25 \%$ & - & - & - & $17 \% \pm 18 \%$ \\
\hline GRAC & - & - & $20 \% \pm 18 \%$ & - & - & - & $20 \% \pm 18 \%$ & - \\
\hline GEM & - & - & $63 \pm \% 50 \%$ & - & $84 \% \pm 44 \%$ & $44 \% \pm 54 \%$ & - & - \\
\hline $\mathbf{T A}$ & $6 \% \pm 19 \%$ & $10 \% \pm 22 \%$ & $10 \% \pm 21 \%$ & $5 \% \pm 21 \%$ & $10 \% \pm 21 \%$ & $16 \% \pm 25 \%$ & $17 \% \pm 27 \%$ & - \\
\hline $\mathbf{T P}$ & $33 \% \pm 34 \%$ & - & - & - & - & $21 \% \pm 49 \%$ & - & - \\
\hline OBE & $16 \% \pm 21 \%$ & $162 \% \pm 10 \%$ & - & - & $50 \% \pm 30 \%$ & - & $17 \% \pm 18 \%$ & - \\
\hline OBI & - & - & - & $50 \% \pm 108 \%$ & $74 \% \pm 51 \%$ & - & - & - \\
\hline SEMIM & - & $40 \% \pm 28 \%$ & $26 \% \pm 24 \%$ & $155 \% \pm 40 \%$ & - & - & $27 \% \pm 23 \%$ & $30 \% \pm 24 \%$ \\
\hline SEMIT & - & $46 \% \pm 31 \%$ & - & - & - & - & $27 \% \pm 24 \%$ & $31 \% \pm 25 \%$ \\
\hline FHL & - & $28 \% \pm 31 \%$ & - & - & - & $18 \% \pm 47 \%$ & - & $37 \% \pm 33 \%$ \\
\hline FDL & - & - & - & - & - & - & - & $74 \% \pm 80 \%$ \\
\hline EHL & - & - & - & - & - & $4 \% \pm 28 \%$ & - & - \\
\hline EDL & - & - & & - & - & - & $10 \% \pm 40 \%$ & - \\
\hline POP & $12 \% \pm 18 \%$ & $10 \% \pm 17 \%$ & $26 \% \pm 34 \%$ & $47 \% \pm 58 \%$ & - & - & $10 \% \pm 17 \%$ & - \\
\hline PEC & $52 \% \pm 29 \%$ & - & - & - & $50 \% \pm 30 \%$ & $27 \% \pm 24 \%$ & - & - \\
\hline PIRI & - & - & - & - & $103 \% \pm 60 \%$ & - & - & - \\
\hline PER & - & - & - & - & - & - & - & $58 \% \pm 17 \%$ \\
\hline $\mathbf{Q F}$ & - & $100 \% \pm 30 \%$ & - & - & - & - & $17 \% \pm 18 \%$ & - \\
\hline
\end{tabular}


Table 3 Changes at the magnitudes of joint forces in response to various muscle impairments. Values are the percentage of rounded average increase or decrease. Negative values demonstrate a reduction in the corresponding joint force compared to the baseline simulations.

\begin{tabular}{|c|c|c|c|c|c|c|c|c|c|c|c|c|c|c|c|c|}
\hline \multirow{3}{*}{$\begin{array}{l}\text { Impaired } \\
\text { muscle } \\
\text { group }\end{array}$} & \multicolumn{6}{|c|}{ Hip } & \multicolumn{6}{|c|}{ Knee } & \multicolumn{4}{|c|}{ Ankle } \\
\hline & \multicolumn{2}{|c|}{$\begin{array}{c}\text { Medial- } \\
\text { lateral }\end{array}$} & \multicolumn{2}{|c|}{$\begin{array}{c}\text { Proximal- } \\
\text { distal }\end{array}$} & \multicolumn{2}{|c|}{$\begin{array}{l}\text { Anterior- } \\
\text { posterior }\end{array}$} & \multicolumn{2}{|c|}{$\begin{array}{c}\text { Medial- } \\
\text { lateral }\end{array}$} & \multicolumn{2}{|c|}{$\begin{array}{c}\text { Proximal- } \\
\text { distal }\end{array}$} & \multicolumn{2}{|c|}{$\begin{array}{l}\text { Anterior- } \\
\text { posterior }\end{array}$} & \multirow{2}{*}{$\begin{array}{c}\text { Medial- } \\
\text { lateral }\end{array}$} & \multirow{2}{*}{$\begin{array}{c}\begin{array}{c}\text { Proximal- } \\
\text { distal }\end{array} \\
\text { Peak }\end{array}$} & \multicolumn{2}{|c|}{$\begin{array}{l}\text { Anterior- } \\
\text { posterior }\end{array}$} \\
\hline & $\begin{array}{c}1^{\text {st }} \\
\text { peak }\end{array}$ & $\begin{array}{c}2^{\text {nd }} \\
\text { peak }\end{array}$ & $\begin{array}{c}1^{\text {st }} \\
\text { peak }\end{array}$ & $\begin{array}{c}2^{\text {nd }} \\
\text { peak }\end{array}$ & $\begin{array}{c}1^{\text {st }} \\
\text { peak }\end{array}$ & $\begin{array}{c}2^{\text {nd }} \\
\text { peak }\end{array}$ & $\begin{array}{c}1^{\text {st }} \\
\text { peak }\end{array}$ & $\begin{array}{c}2^{\text {nd }} \\
\text { peak }\end{array}$ & $\begin{array}{c}1^{\text {st }} \\
\text { peak }\end{array}$ & $\begin{array}{c}2^{\text {nd }} \\
\text { peak }\end{array}$ & $\begin{array}{c}1^{\text {st }} \\
\text { peak }\end{array}$ & $\begin{array}{c}2^{\text {nd }} \\
\text { peak }\end{array}$ & & & $\begin{array}{c}1^{\text {st }} \\
\text { peak }\end{array}$ & $\begin{array}{c}2^{\text {nd }} \\
\text { peak }\end{array}$ \\
\hline $\begin{array}{c}\text { Hip } \\
\text { extensor }\end{array}$ & $-17 \%$ & $32 \%$ & $10 \%$ & $10 \%$ & $1 \%$ & $16 \%$ & $7 \%$ & $17 \%$ & $11 \%$ & $18 \%$ & $7 \%$ & $6 \%$ & $10 \%$ & $11 \%$ & $2 \%$ & $30 \%$ \\
\hline Hip flexor & $36 \%$ & $30 \%$ & $20 \%$ & $24 \%$ & $20 \%$ & $31 \%$ & $5 \%$ & $-1 \%$ & $7 \%$ & $1 \%$ & $6 \%$ & $4 \%$ & $11 \%$ & $11 \%$ & $2 \%$ & $10 \%$ \\
\hline $\begin{array}{c}\text { Hip } \\
\text { abductor }\end{array}$ & $-20 \%$ & $10 \%$ & $22 \%$ & $11 \%$ & $25 \%$ & $17 \%$ & $22 \%$ & $23 \%$ & $32 \%$ & $19 \%$ & $18 \%$ & $8 \%$ & $9 \%$ & $11 \%$ & $3 \%$ & $14 \%$ \\
\hline $\begin{array}{c}\text { Hip } \\
\text { adductor }\end{array}$ & $-9 \%$ & $35 \%$ & $30 \%$ & $20 \%$ & $30 \%$ & $24 \%$ & $15 \%$ & $20 \%$ & $28 \%$ & $17 \%$ & $5 \%$ & $14 \%$ & $6 \%$ & $8 \%$ & $-9 \%$ & $15 \%$ \\
\hline $\begin{array}{c}\text { Knee } \\
\text { extensor }\end{array}$ & $34 \%$ & $21 \%$ & $17 \%$ & $18 \%$ & $13 \%$ & $26 \%$ & $-20 \%$ & $-23 \%$ & $-5 \%$ & $-10 \%$ & $14 \%$ & $-10 \%$ & $14 \%$ & $10 \%$ & $3 \%$ & $2 \%$ \\
\hline $\begin{array}{l}\text { Knee } \\
\text { flexor }\end{array}$ & $36 \%$ & $25 \%$ & $10 \%$ & $10 \%$ & $7 \%$ & $25 \%$ & $-10 \%$ & $-27 \%$ & $-8 \%$ & $-18 \%$ & $-2 \%$ & $-30 \%$ & $7 \%$ & $6 \%$ & $-2 \%$ & $-12 \%$ \\
\hline $\begin{array}{c}\text { Ankle } \\
\text { plantar } \\
\text { flexor }\end{array}$ & $20 \%$ & $13 \%$ & $16 \%$ & $12 \%$ & $12 \%$ & $10 \%$ & $8 \%$ & $14 \%$ & $10 \%$ & $14 \%$ & $8 \%$ & $20 \%$ & $10 \%$ & $23 \%$ & $-16 \%$ & $-8 \%$ \\
\hline $\begin{array}{c}\text { Ankle } \\
\text { dorsiflexor }\end{array}$ & $22 \%$ & $13 \%$ & $17 \%$ & $12 \%$ & $15 \%$ & $10 \%$ & $8 \%$ & $10 \%$ & $10 \%$ & $11 \%$ & $8 \%$ & $5 \%$ & $14 \%$ & $10 \%$ & $-14 \%$ & $39 \%$ \\
\hline
\end{tabular}

